\title{
LAPSE AND REINSTATEMENT
}

\author{
$\mathrm{By} \mathrm{J} . \mathrm{H}$. JeFFeries,
}

Home Office, The Penn Mutual Life Insurance Company.

The procurement of new business and its retention are the two great problems of life insurance management. These two branches of our work are closely related, or interrelated, and upon their proper administration depends the development and growth of a company and its consequent success, measured in results which will be equitable alike to persisting policyholders and to those whose insurance terminates by death, maturity or withdrawal.

Life insurance companies are organized for the purpose of providing protection against pecuniary loss through death, and however they may differ in plan of organization, charter or by-law they are essentially alike in that they are associations of individuals uniting in a common cause against man's ancient and familiar enemy.

Ord-line, or level premium companies, are divided generally into two classes; first, mutual companies, having no stock capital, and which are controlled by the policyholders themselves, or as they are more properly designated, the members; and, second, stock companies, where the control of the company is with the shareholders, and in which the capital stock is held as an additional security for the protection of policyholders. Practically, however, there is little difference between the two classes, for the reason that the business generally, so far as it relates to the actual matter of insurance, is conducted upon the mutual plan. Criticism has been made of the stock plan because of the opportunity it affords to those who control the majority interest for a selfish manipulation of policyholders' accumulations; on the other hand, the same criticism might be made, and with equal propriety, with respect to those companies organized on the mutual plan, whose charters permit the use of proxies in voting for trustees. 
All this is aside from our subject, perhaps, except as it leads up to this proposition, that in all companies, however constituted, a just regard for the equities of those who associate themselves together for reciprocal prctection, whether they are termed members or policyholders, or whatever else they may be called, and whether continuing or retiring, should be the first consideration of every life insurance manager in the faithful execution of the sacred trust which the nature of his services imposes upon him.

A policy of life insurance is a contract, based upon the same common law principles which are fundamental to every other legal contract or binding agreement. There must be a subject matter upon which the minds of the parties can agree; there must be an offer on the one side and acceptance on the other; there must be no mistake or misunderstanding to render it voidable; it must be free from the vitiating influences of fraud; and, finally, when the body of the contract is thus constructed, there must be a consideration to give it life. Blackstone defined a policy of insurance as "a contract between $A$ and $B$, that upon A's paying a premium equivalent to the hazard run, $B$ will indemnify or insure him against a particular event." This definition, though written nearly one hundred and fifty years ago, is true to-day, for no matter what nay be the terms of any particular policy with respect to time or manner of payment of the sum insured, whether it be gold bond, trust certificate, limited payment, whole life, endowment or what-not, the essence of every policy is the contractual relation between the partics, based upon an equivalent consideration or premium. The actuary will describe to you the factors of mortality, interest and expense loading which go to make up the sum of a premium, but for our purpose it will be sufficient to look upon it in its entirety, always keeping in mind, however, that upon its payment on the dates agreed upon is predicated the very life of the contract itself. The premium is, therefore, a continuing consideration, renewable from year to year. The option of renewal is always with the policyholder, and in this sense a policy is a unilateral contract. The insuring company must fulfill its conditions so long as the premium is paicl, and, under certain conditions, for many years thereafter, while the policyholder may renew or discontinue as he may choose, or as circumstances may compel. When a premium is not paid or otherwise settled on its due date, the policy is said to lapse, subject always 
to its non-forfeiture provisions, of which we shall speak more fully later.

It is interesting to note the etymology of the word "lapse." It is derived from the Latin word lapsare, to slip, to fall, to stumble, and this original meaning of the word is aptly descriptive of those whose misfortune it is to fall by the way, and who, whether through choice or necessity, thus cast aside the burden of the obligation to provide for those who are dependent upon them.

As what I shall have to say on the subject of lapse and reinstatement will have particular reference to that form of insurance association, whether stock or mutual, known as old-line or level premium companies, a word in explanation of that term will be appropriate at this point. Briefly, a level premium company is one in which the premium or annual consideration for the benefit to be received is leveled to an equal annual charge by the application of the law of average to the mortality table selected. When this is done it follows that the annual charge will be more than sufficient to pay for the risk incurred during the early years of the policy, when the chances of dying are relatively small. This overcharge is necessary, however, in order that the excess accumulated at compound interest, may be adequate to make up the deficiency in the later years, the premium itself not being competent to carry the load as the certainty of death becomes more imminent, for while "the young may die, the old must." Each member is thus building a self-insurance fund, and if a member survive the age limit contemplated by the mortality table in use, the sum of his net premiums, at the rate of interest assumed, will equal the face value of his policy. It is apparent, then, that from the first year of the contract, and during the currency of the insurance period, the company holds in trust for each member, an ever-increasing fund, or as it is commonly called, a reserve. In the event of the termination of the contract, this reserve fund is variously applied. If the termination be by death, the reserve, together with whatever sum is then necessary to bring the total to the amount assured, is turned over to the beneficiary under the policy. The difference between the reserve and the amount required represents the cost to the company. Where policies terminate by maturity, the date of termination having been predetermined, so far as the endowment feature is concerned, the reserve will, of course, equal the amount agreed to be paid. 
In the case of terminations by expiry, as under term insurance contracts and extended insurance, the rate charged carries the insurance to a certain point, beyond which there is no remaining value, the credits and debits balance, and the account is closed. But what of those who withdraw before death or maturity, and what disposition shall be made of the reserves which they have accumulated? These are the questions to which our discussion naturally leads, and in order that some idea of the importance of their proper solution, both to company and policyholder, may be obtained, it will be well at this point to consider for a moment some figures compiled from the statements of all the companies reporting to the various insurance departments as to their business in 1903, the latest statistics available. These companies showed insurance in force on January I, I903, amounting to $\$ 8,698,000,000$. They issued during the year $\$ 1,908,000,000$ of new insurance. These two items amount to over $\$ 10,606,000,000$. The insurance in force at the end of the year was reported at $\$ 9,569,000,000$; showing that the total terminar tions from all causes during the year reached the sum of $\$ 1,037,000,-$ $\infty 00$. Of this amount, $\$ 112,121,000$ was terminated by death, $\$ 27,-$ 000,000 by maturity, $\$ 13,800,000$ by expiry, $\$ 181,180,000$ was the sum of new policies "not taken," while the aggregate withdrawals by surrender and lapse amounted to $\$ 530,494,000$.

We have already noted the effect of terminations by death, maturity and expiry upon the policyholder's reserve. With the "not takens" we need have little concern. They come still-born into the insurance family. They represent chiefly disappointed hopes on the part of the solicitors who wrote the applications. They had only the form of being, for into them was never breathed the vivifying influence of the premium consideration, and they are crossed off the policy register with regret only for what they might have been.

Lapses, on the other hand, represent cases which have been nourished through infancy with the milk of new commissions, medical fees, agency expenses, and mortality risk, and their going out means actual loss to a company when the withdrawal occurs within two or three years after issue, or to keep up our simile, before the new members of the insurance family become contributing or selfsupporting. In this connection it should be pointed out, however, that the gain from light mortality among selected lives during the first years of the risk offsets, to some extent, the initial expense. 
Statisticians tell us that from $17 \% / 2$ per cent. to 18 per cent. of new issues will fail of renewal upon the first anniversary of the policy, 8 per cent. of that which remains will lapse when the third payment is due, and thereafter in reducing percentage from year to year as the policies become older.

Lapse ratios are calculated on the relation which the amount thus terminated in any year bears to the mean insurance in force, and as lapses have been shown to be most frequent during the early years, it follows that a company producing a large new business will show a larger lapse ratio than one writing a comparatively small new business, but with a great number of old policies on its books. The managers of progressive companies, however, consider it their duty to extend the benefits of insurance to the largest possible number of insurants that a consistent regard for safety and reasonable cost to all will permit, and if in doing this some are attracted who will later withdraw, their withclrawal is looked upon as one of the penalties of progress, but nevertheless a thing to be controlled or avoided as far as possible.

In any comparison of the experience of companies in this regard, it is also important to keep in mind that the same methods of bookkeeping do not obtain in all companies. For instance, one of the New York companies reported terminations "by expiry" in 1903 as $\$ 74,358,000$, and "by lapse" the sum of $\$ 7,005,000$, while another company, practically its equal in size and writing the same class of business, reported expirations of only $\$ 998,000$ and lapses amounting to $\$ 62,012,000$. In one company a member who fails to renew by the payment of the second year's premium is evidently given a few days' extension, and, if the overdue premium is not settled at the end of the extended period, the termination is said to be "by expiry;" the other company calls a lapse a lapse. Obviously any comparison based upon such divergent factors would be false and misleading. Comparative exhibits, and especially those having to do with ratios of this to that, or of that to this, should be carefully analyzerl before making any deductions as to the relative merit of different companies.

Much speculation has been indulged in as to the causes of lapse. They are, to a large extent, natural, inevitable and unavoidable. Misfortune, loss of position, unrealized expectations, all contribute to the volume of withdrawals. Over-persuasion on the part of zeal- 
ous solicitors is responsible for a large portion. Again, many men take insurance as the result of impulse rather than conviction, and, like New Year's resolutions or the keeping of a personal cash account, it is soon tired of and neglected. The seed fell on stony ground and sprang up, but the sun scorched it because it had not much root and it withered away. The thrifty man, whose insurance is taken out because of a deeply rooted conviction of its value, will continue, while the improvident will lapse.

It was at one time generally held that lapsing members exercised an adverse selection against a company in that only those who were in good health would retire and the unhealthy or impaired remain, and that the eventual result of this selection would be an increased mortality experience. While there is no doubt that there is a certain degree of truth in this view, it is unquestionably the fact that the main cause of lapse is financial embarrassment. On the other hand, those who sustain their insurance are the prudent and prosperous, who are generally the most desirable risks, not only because of their ability to pay, but also for the reason that the same qualities of prudence and economy which engender thrift, work to promote their physical well-being also, and their continuance operates to maintain an average mortality as against the adverse selection to which we have referred.

In any honest inquiry into the causes of lapse, our eyes should not be closed to the effect of the improper methods employed by some solicitors to obtain new business. By improper methods, I mean misrepresentation of policy contracts, such as selling a limited payment life contract for an endowment, rebating, twisting a policyholder from one company to another, over-persuasion to assume an obligation which obviously cannot be fulfilled, extravagant estimates, and the like, and they are all prolific of lapse. I do not mean to infer that these methods are peculiar to or are encouraged by any particular company. They force their noxious and unwelcome presence into every field.

It is an axiom of our business that prevention of future lapse should begin when the application is written. A company's reputation in any locality depends largely upon the character and methods of its solicitors. Its officers and field managers may be men of high standing and undoubted integrity, but it will be adjudged worthy or otherwise as it is reffected in the work of the solicitor. 
If the mirror be not true a distorted image will be presented. A solicitor who cheapens a policy he is trying to place by rebating a portion of the first year's premium destroys the confidence of insurers in his company. "Easy come, easy go," is an old adage, and true of our work, as of other things, and the natural result of rebated business is seen in the failure to collect the second year's premium. The practice renders full premiums in other cases more difficult of collection and discredits the agent, not only in his own community but at the home office also, for the company requires not only the form of production but the substance as well. If an application is procured in such a manner as to obtain the confidence of the applicant, the chances are that he will consult the agent before withdrawing, or taking other insurance elsewhere.

Having discussed the causes of lapse, I will pass at once from this unpleasant phase of our subject to a consideration of the effect of lapse upon the policy contract itself. In the early days of life insurance in this country the failure to pay a premium on its due date resulted in an absolute and immediate forfeiture, and the ironclad policies then in vogue exposed a policyholder to the same risk in many other ways. Change of residence or occupation, traveling beyond certain carefully defined limits without previous permission endangered the existence of the policy as a means of protection, no matter how many premiums the insured had paid nor how much he had contributed to the common fund. In fact one old policy is said to have contained the provision that if the insured should die without the written consent of the company, the policy would be void, though, of course, this statement had no other foundation in fact than an awkward phrasing of the policy terms.

The following clauses are quoted from a policy issued in 1847 by a representative American company:

"It is hereby declared to be the true intent and meaning of this policy . . . that in case the said assured shall without the consent of this company previously obtained, and endorsed upon this policy, die upon the high seas, or pass beyond the settled limits of the United States (excepting into the settled limits of the British provinces of the two Canadas, Nova Scotia or New Brunswick), or shall, without such previous consent, thus endorsed, visit those parts of the United States which lie south of the southern boundaries of the States of Virginia and Kentucky, between the first of July and the first of November, or shall, without such previous consent thus endorsed, enter into any military or naval service whatsoever (the 
militia not in actual service excepted), or in case he shall die by his own hand, whether sane or insane, or in, or in consequence of a duel, or by the hands of justice, or in the known violation of any law of any of these states, or of the United States, or of any state or county, this policy will be null, void and of no effect."

"And it is also understood and agreed . . . that if the declaration made by the said assured . . . shall be found in any respect untrue, then . . this policy shall be null and void . . ."

"And it is further agreed that in every case where this policy shall cease and determine, or become or be null or void (except in case of death), all previous payments made thereon . . . shall be forfeited to the said company."

Then follows a clause to the effect that if the policy were assigned without the approval of the company and the assignment endorsed on the policy within thirty days from its date the premiums paid would "be considered sunk for the benefit of the assurers."

In striking contrast to this ancient document, let me call your attention to the form of policy now in use by the same company as illustrating the progress which has been made. On its face it is practically a simple promise to pay in consideration of the premium named. It provides that "from the date of issue it shall be without any restrictions as to travel, residence or occupation." It is "absolutely incontestable for any cause after one year from date of issue, except non-payment of premium;" but in case of suicide, whether sane or insane, within one year from the date of the policy the liability of the company is limited to the amount of the premium paid. Printer in the policy, and made a part of the contract, are the guaranteed extended insurance, paid-up and cash surrender privileges available after lapse at the end of the years stated. This policy is in no sense unusual, but is fairly representative of the contracts now in use by all the American companies.

Three factors have united to bring about the change:

First.-Greater knowledge of the science of insurance;

Sccond.-Legislation; and

Third.-Competition.

During the period of twenty years immediately preceding the outbreak of the Civil War many of the companies which are now the recognized leaders in life insurance enterprise were just beginning their work. Life insurance in this country was in its infancy. Its [276] 
unclerlying principles were but little understood, and policies were "clad with iron" as a means of protection against unknown and fancied dangers, rather than from any desire to force withdrawals, or to derive profit therefrom. Whatever gains did accrue from this source were regarded as rightfully belonging to the persisting members, and they account in some measure for the large dividend returns of those early days. So competent an authority as Dr. Bloomfield J. Miller is quoted as saying in a recent lecture in the Yale insurance course that "there was nothing in the old days of life insurance which life insurance managers feared so much as the voluntary withdrawal of policyholders owing to their failure to continue premium payments. It was for this reason that companies made policies absolutely forfeitable for non-payment of premium. As the companies grew older and policies more valuable, such an absolute forfeiture began to be recognized as an unconscionable penalty for the discontinuance of the policy contract." With experience, however, came knowledge, and with knowledge wisclom, and in about the year 1860 we see evidences of a recognition on the part of the managers of the equity of lapsing members in the reserves which they had accumulated. Paid-up policies for a recluced amount were allowed in exchange for a surrender of the policies, providing application were made therefor within a stated period. These paid-ups were based upon the purchasing power of the reserve at the attained age of the insured, first deducting a surrender charge or fine for withdrawal. The reason for the surrender charge is obvious if we bear in mind that the whole scheme of insurance is based upon averages; a policyholder is but one of many, and his retirement as a contributing unit affects the status of all who remain. The justice of a reasonable fine for withdrawal has always been conceded and it is still the practice to impose it.

The granting of paid-ups was a decided advance and marked the beginning of a new era in life insurance, for the liberalization of policies operated to remove much of the popular prejudice against the system, and managers began to see that the effect of anly adverse selection which might be exerted against a company because of the removal of the penalty of absolute forfeiture for lapse, would be largely counter-balanced by gains in membership.

Coincident with the development of this liberalizing tendency, the newly organized insurance department of the State of Massachu- 
setts was exerting a powerful influence in the same direction. Elizur Wright was one of the greatest authorities on the science of life insurance this country has ever produced. He was one of the insurance commissioners of Massachusetts during the years 1859 to 1865 , and the Massachusetts insurance reports covering that period are regarded as classics of insurance literature. Mr. Wright strongly advocated the enactment of a law compelling companies organized in Massachusetts to apply the reserve of lapsing members to the purchase of extended insurance. I quote from the report of 1859: "We do not think it would be a law impairing the just obligation of contracts, but quite the contrary, which should enact that hereafter any policy . . . after lapse for non-payment of premium should nevertheless be good against the company in case of death, should that event occur before the value of the policy, at the time the last premium was due, should be exhausted in temporary insurance." And again: "Let the failure to pay the premium as stipulated only release the company from the obligation to insure beyond the time and amount already paid for. Apart from the consideration of justice to the insured, we believe policies under a legal provision of this kind would be greatly preferred and would attract business to the companies. issuing them. Profits caught by the trap of forfeitures frighten away ten times their amount, deterring the most prudent people from running the hazard of life insurance." $\mathrm{Mr}$. Wright's arguments prevailed and his recommendations were adopted by the Massachusetts Legislature in 186r, when the first non-forfeiture law was enacted.

The act was subsequently amended in several particulars, and now provides that after three full annual premiums have been paid under a life or endowment policy a paid-up or cash surrender value must be granted.

Following the lead of Massachusetts, the States of California, Colorado, Kentucky, Maine, Michigan, Missouri, New Jersey and New York, and perhaps others, have placed non-forfeiture laws upon their statute books.

The New York statute is fairly representative of the character of these laws, and is in part as follows:

"Whenever any policy of life insurance . . . after being in force for three full years, shall, by its terms, lapse or become forfeited for the nonpayment of any premium . . . the reserve on such policy, computed 
according to the American experience table of mortality at the rate of $4^{T / 2}$ per cent. per annum, shall, on demand made, with surrender of the policy within six months after such lapse or forfeiture, be taken as a single premium of life insurance at the published rates of the corporation at the time the policy was issued, and shall be applied, as shall have been agreed in the application or policy, either to continue the insurance of the policy in force at its full amount so long as such single premium will purchase temporary insurance for that amount at the age of the insured at the time of lapse or forfeiture, or to purchase upon the same life at the same age paid-up insurance, payable at the same time and under the same conditions, except as to payments of premiums, as the original policy."

The further enactment of laws of this character is unnecessary for the reason that the companies themselves now grant more liberal terms to lapsing members than are required by law. In fact, competition for new business is now so keen that some of the companies appear to have gone to the other extreme and, in some instances, allow values even greater than the apparent reserves surrendered.

In our work, as in every other branch of human endeavor, competition, comparison and criticism are requisite to the production of best results. Had there been but one company, or had all the companies united in an agreement to control the business, the inequitable iron-clad policy of former days would still obtain, except as it might have been affected by the operation of law. However that may be, and despite all that has been frenziedly written upon the subject, the companies are acting independently of each other. In the strife for business each seeks to render its policies the most attractive, and the modern life insurance contract, with its freedom from unnecessary restrictions and unjust conditions is the fruitage of years of competitive enterprise.

We do not know where a recent writer, who is attracting considerable notoriety, obtained his data for the warning which he gives to policyholders not to lapse their insurance, claiming that that is just what the companies desire. Whether conceived in ignorance or mendacity the claim is absolutely false, for not only through the non-forfeiture provisions of their policies do the companies preserve the equities of lapsing members, but they strive to prevent lapse by offering every possible aid to continuance, such as temporary notes, premium loans, cash loans and premium extensions. At the present time thousands of Southern policyholders who cannot pay their premiums because of the low price of cotton, are being 
carried by the companies, whereas if strict adherence to policy conditions were insisted upon, they would be compelled to lapse.

Out of fifty-four policies examined, forty-seven allow thirty days' grace within which to pay premiums. The others have no grace clause, but have their own individual practice of aiding in the renewal of business, the general rule being to accept settlement of an overdue premitum if tendered within thirty days after date, providing the policyholder is then in good health. My personal view is in accord with the minority practice in this regard. I do not believe that it is wise to incorporate a clays of grace clause in the contract. General extensions of this character tend to encourage carelessness and negligence. In any individual case any reasonable accommodation can always be obtained upon written or personal request, and a system which permits temporary notes, premium liens and time extensions affords ample protection to all, while it places the opportunity and responsibility of renewal where they rightfully belong-with the member himself. Justice to all members requires the payment or other settlement of premiums upon their due dates, as the acceptance of overdue premiums will establish a custom upon which policyholders may reasonably rely. Companies have been held liable because of lax methods in this regard, and in some cases the "custom" has been successfully pleaded when death has occurred, and where, as a matter of fact, there was little doubt but that the delinquent intended to discontinue.

Let me turn now and for a few moments only to the subject of reinstatement. It will be reaclily appreciated that this is a branch of life insurance management demanding the most careful administration. Where a lapsed member desires to revive his insurance the question of motive must be considered, for the query naturally arises: why does he wish to renew? If no conditions were imposed many of those who, after lapse, had become sick or injured, would hasten to renew their membership and thts secure the full measure of the protection they had forfeited or climinished. A company must, therefore, in self-defence require satisfactory evidence of insurability before reinstating a delinquent. In order to protect themselves against impaired risks, the practice of all the companies is to require a certificate of good health, to be signed by the policyholder and local official examiner. Many companies require a written application for revival in addition to the health certificate. A 
regularly appointed examiner must be employed for the reason that, however honest the family physician may be, his friendship and sympathy might have a tendency to influence his judgment. A complete re-examination is required by some companies when the request for revival is made more than six months after lapse.

The policies of the different companies contain varying clauses with respect to reinstatement. Out of fifty-four contracts examined seventeen agree to reinstate at any time after lapse, providing satisfactory evidence of good health is furnished and the overdue premiuns, with interest, are paicl; twenty-one limit the time within which policies may be reinstated to periods ranging from six montlis to five years after lapse; fourteen have no clause in their contracts, but reinstate upon proof of insurability. Some of the above have further limitations with respect to reinstatement within the deferred or tontine dividend period; while one provides that a tontine dividend policy cannot be restored as such later than sixty days after default. Some of the companies require the payment of any outstanding indebtedness against a policy, as well as the overdue premiums and interest. This practice hinders reinstatement, as it frequently requires the payment of a sum beyond the means of a policyholder. It is a simple matter of bookkecping to adjust the loan on the reinstated policy, and it would seem to be better practice to require only the overdive premiums and interest and to reimpose the former liens. If the policy, before lapse, was sufficient collateral for the indebtedness it is certainly more than adequate after the payment of adclitional premiums.

Reviewing the whole subject, it appears that the present practice of the companies with respect to reinstatement is in keeping with the other liberal features of their contracts and shows that they stand ready to welcome back into membership all who are insurable, rather than to take advantage of their temporary necessities or forgetfulness.

Many of the companies have recently organized home office departments for the revival of lapsed policies. The methods employed by the company with which I am connected are as follows: Our agents are requested to enter the names and addresses of all persons who fail to renew in the blank furnished for that purpose. We then forward a letter to these persons, regretting the loss to company and member, suggesting the possibility of aid, and inviting 
correspondence. We do not overlook the reply-provoking influence of a two-cent stamp and therefore enclose a stamped return envelope. If this brings an answer the status of the policy is investigated and an offer suitable to the situation is made. Another plan is to write a personal letter in every case where a policy has value, suggesting the disadvantage and loss to the member of discontinuing a policy upon which a stated number of payments has been made, the advantage of retaining the benefit of the rate for younger age, etc. In the past year 30 per cent. of these special cases were reinstated by the home office, while others were revived through the agencies after the receipt of our letter.

When a policy is reinstated through our efforts no reflection is cast upon the agent, for we base our work on the presumption that when a renewal receipt is returned for cancellation, the agent has exhausted every means at his command to induce the continuance of the policy. When he fails, we take it up, and we succeed in reviving many cases, not because we can offer, or do offer more, but because a personal communication from an officer is often esteemed a compliment. Members like to be noticed officially, and to feel that they are thus coming into close touch with the management. We, of course, do all we can to encourage that feeling, and, in the event of revival, cheerfully turn the renewal commission over to the general agent. It is cheaper to do this than to replace a lapse with a new policy costing many times more.

In bringing this paper to a conclusion, let me say in all seriousness and with absolute sincerity of purpose, that aside from whatever pecuniary interest the companies may have in these matters of lapse and reinstatement, the officers are moved and controlled by this higher thought and motive: To safeguard policyholders against their own negligence, carelessness or misfortune, and to prevent, in so far as it is possible to do so, the loss of the protection to family and dependent ones which was planned for them and to which they are entitled. 